\title{
Involvement of Serum Uric Acid in Essential Hypertension, Progressive Proteinuria and Impairment in Renal Function among Type-2 Diabetic Patients
}

\section{Kamran Mahmood Ahmed Aziz*}

Consultant Diabetes and Metabolism, Research Scientist and Clinical Investigator, Aseer Diabetes Center of Aseer Central Hospital, Ministry of Health, Abha, Saudi Arabia

*Corresponding author: Kamran Mahmood Ahmed Aziz, Consultant Diabetes and Metabolism, Research Scientist and Clinical Investigator, Aseer Diabetes Center of Aseer Central Hospital, Ministry of Health, P.O.Box 34, Abha, Saudi Arabia, Tel: 00966-568361040; E-mail: drkamran9999@yahoo.com

Received: 01 Mar, 2021 | Accepted: 10 Mar, 2021 | Published: 19 Mar, 2021

Citation: Aziz KMA (2021) Involvement of Serum Uric Acid in Essential Hypertension, Progressive Proteinuria and Impairment in Renal Function among Type-2 Diabetic Patients. Int J Nephrol Kidney Fail 7(1): dx.doi.org/10.16966/2380-5498.206

Copyright: (c) 2021 Aziz KMA. This is an open-access article distributed under the terms of the Creative Commons Attribution License, which permits unrestricted use, distribution, and reproduction in any medium, provided the original author and source are credited.

\begin{abstract}
Type-2 diabetes is a metabolic disorder with vast complications. Uric acid (UA) was recently discovered as a risk biomarker for the development of type-2 diabetes. Several studies have found a significant association of Hyperuricemia with Hypertension (HTN), renal complications and cardiovascular disease. However, no study has found an association of hyperuricemia with the development of essential hypertension, nephropathy and Diabetic Kidney Disease (DKD) among type-2 diabetics. Moreover, in the past no study has found cut off points for serum uric acids for the development of DKD/CKD among diabetics with sensitivity and specificity, which was achieved in the current study. We collected 10,300 type-2 diabetics data for more than 15 years in a cross sectional retrospective manner. $17 \%$ demonstrated hyperuricemia while $16 \%$ were found to be DKD. Significant correlations were found between serum UA and other variables (serum creatinine, systolic and diastolic BP, microalbumin and spot urine protein). Levels of UA were observed to be elevated among patients with HTN, nephropathy and DKD ( $<<0.0001)$. Similarly, serum creatinine, systolic and diastolic BP, microalbuminuria and spot urine protein were higher for the group with hyperuricemia $(p<0.0001)$. Pearson's $\left(\chi^{2}\right)$ and logistic regression with odds ratio demonstrated that hyperuricemia was significantly associated with HTN (odds ratio $2.5 ; 95 \% \mathrm{Cl} 1.8$ to 23.4 ; $\mathrm{p}<0.0001$ ). Similarly, hyperuricemia was significantly associated with the development of nephropathy and DKD/CKD; odds ratio 2.1 (95\% Cl 1.46 to 2.8; $p<0.0001)$ and $27.3(95 \% \mathrm{Cl} 14$ to 53; $p<0.0001)$, respectively. Moreover, regression model between serum UA and serum creatinine was also significantly associated with each other and proves our hypothesis that UA linearly causes an increase in the blood creatinine with the following relationship : Serum creatinine $=0.221+[0.154 \times$ serum UA]. ROC for DKD and serum UA demonstrated that with AUC of $0.98(95 \% \mathrm{Cl} 0.961$ to 0.986$)$, UA level of 6.8 was $91 \%$ sensitive and $79 \%$ specific for the development and significant association with DKD/CKD ( $p<0.0001)$. This is the first study of its kind that has demonstrated significant associations of UA with HTN, nephropathy and DKD. It is the time to revise the normal levels of UA among type-2 diabetics and to initiate regular screening for hyperuricemia to prevent further diabetes complications.
\end{abstract}

\section{Introduction}

Diabetes mellitus is a major endocrine problem with severe complications if other co-morbidities are not screened early in the course of disease. Several biomarkers, including uric acid, are involved in different diabetic complications [1,2]. Uric acid is a product of purine metabolism, which degraded in mammals by the hepatic enzyme, urate oxidase or uricase. The end product, allantoin, is freely excreted in the urine. Hyperuricemia is usually defined as $>7.0 \mathrm{mg} /$ $\mathrm{dL}$ in men and $>6.0 \mathrm{mg} / \mathrm{dL}$ in women. High levels of UA should be managed with lifestyle, dietary counselling or pharmacotherapy. If untreated, high UA levels can lead to gouty arthritis with other rheumatology complications with renal involvement among nondiabetics and diabetics.
Uric acid has been shown to be involved in endocrine abnormalities. Recent research has demonstrated that UA is frequently associated and is an independent risk factor for type- 2 diabetes, obesity, metabolic syndrome, hypertension and renal disease. In patients with obesity, insulin resistance, and dyslipidaemia, hyperuricemia frequently occurs because insulin stimulates sodium and urate reabsorption in the proximal tubule $[3,4]$. Past and emerging data had suggested that an increased UA level is one of the most important risk factors for cardiovascular disease [5-12]. Diabetes itself is associated with microvascular complications [13-15].

Although several trials have demonstrated the association of UA with hypertension and renal dysfunction, no study has found cut off points for UA and its association with hypertension and the development of Diabetic Kidney Disease (DKD) among diabetics. 
Hence, the aim of the current study was to explore these comorbid associations and to find UA cut off points for sensitivity and specificity to initiate early treatment and preventing UA associated diabetic complications.

\section{Study Design and Methods}

This was a prospective cross sectional cohort study, conducted at the diabetology clinic of Aseer Endocrine and Diabetes Center, Aseer Central Hospital, Saudi Arabia. The study was initiated in August 2005 until February 2021, more than fifteen years of duration. Only type-2 diabetic patients were selected. Children, patients with liver disease, End Stage Renal Disease (ESRD), and pregnant patients were excluded from this study. Blood Pressure (BP) was measured by standardized methodology. BP of $\geq 140 / 90$ was labeled as Hypertension (HTN). Fasting blood samples were taken for chemistry.

Uric acid was measured by URCA method used in the dimension $\mathrm{R}$ clinical chemistry system, an in vitro diagnostic intended for the quantitative determination of UA in human serum and plasma (Siemens healthcare diagnostics Inc. Newark, DE 19714, USA). The UA method is a modification of the uricase method first reported by Bilger and Johns. Uric acid, which absorbs light at $293 \mathrm{~nm}$ is converted by uricase to allantoin, which is non-absorbing at $293 \mathrm{~nm}$. The change in absorbance at $293 \mathrm{~nm}$ due to the disappearance of UA is directly proportional to the concentration of UA in the sample and is measured using a bichromatic (293,700 nm) endpoint technique. UA levels of $\geq 7$ $\mathrm{mg} / \mathrm{dl}$ were labelled as "hyperuricemia".

Serum creatinine $(\mathrm{mg} / \mathrm{dl})$ was quantitatively measured by CREA methodology by Dimension ${ }^{\otimes}$ clinical chemistry device (Siemens Healthcare Diagnostics Inc. Newark, DE 19714, USA). This procedure involves picrate for the measurement of creatinine in plasma and urine. Patients with serum creatinine $\geq 1.5 \mathrm{mg} / \mathrm{dl}$ were considered as potentially having Chronic Kidney Disease (CKD) or Diabetic Kidney Disease (DKD). Nephropathy was ruled out by the measurement of albumin or protein in urine. QuikCheck ${ }^{\mathrm{mot}}$ urinalysis reagent strips (ACON biotech, Co., Ltd.) was used to detect macroalbuminuria or gross proteinuria using $\mathrm{pH}$ indicators. Urine samples with gross proteinuria by the color change of the reagent strips (from $1+$ to 4 + proteins) were considered "nephropathy". Microalbumin was detected in urine by MALB method (Dimension " clinical chemistry system device, Siemens Healthcare Diagnostics Inc. Newark, DE 19714, USA). This measures albumin in vitro quantitatively $(\mathrm{mg} / \mathrm{L})$ by Particle-Enhanced Turbidimetric Inhibition Immunoassay (PETINIA) methodology by color change. Urine samples positive for microalbuminuria were again labeled as nephropathy. Spot urine protein was measured by Dimension ${ }^{\star}$ clinical chemistry system (Siemens healthcare diagnostics Inc. Newark, DE 19714, USA). This detects in vitro total protein in human urine by pyrogallol red molybdenum method (Y. Fujita, I. Mori and S. Kitano methodology).

Clinical data was analyzed by $\mathrm{IBM}^{\circledR}$ SPSS $^{\circledast}$ statistics, version 20 (IBM Corp). Data was summarized as percentages with eMan \pm SD and $95 \%$ CI. Independent $t$-test was used to test the significance between the groups of variables. Pearson chi-square $\left(\chi^{2}\right)$ was used to find significant associations among variables. Logistic Regression, Odds Ratio were also used to measure associations between different variables. ROC was used to find cutoff values, sensitivity and specificity of UA for the development of DKD. Statistical power of $90 \%$ and p-values (twosided) of less than 0.05 were considered significant. The study was reviewed and approved by the research committee of Aseer Diabetes and Endocrine Center, and all methodologies on subjects use reported in accordance with the Helsinki Declaration.

\section{Results}

A total of 10,300 patient's data was analyzed in this study. Tables 1 and 2 demonstrate demographic data and descriptive statistics, respectively. High levels of UA ( $\geq 7 \mathrm{mg} / \mathrm{dl}$ ) were observed in $13 \%$ of patients. $42 \%$ were hypertensives and $16 \%$ with $\mathrm{DKD} / \mathrm{CKD}$.

Demographic data is demonstrated in table $1.12 \%$ of patients demonstrated diabetic foot infection. Nephropathy was observed in $39 \%$ of patients; $43 \%$ were hypertensive and $15 \%$ demonstrated DKD/ CKD. Descriptive statistics for variables are shown in table 2.

Significant t-test statistics among group of variables is presented in table 3 with significant p-values. Levels of UA were observed to be elevated among patients with HTN, nephropathy and DKD. Similarly, serum creatinine, systolic and diastolic BP, microalbuminuria and spot urine protein were higher for the group with hyperuricemia, with significant p-values. Box plot of serum UA levels with and without DKD is presented in figure 1 and table 4 demonstrates Pearson's correlations between variables with p-values.

Pearson's $\left(\chi^{2}\right)$ and logistic regression with odds ratio, regression Model and ROC statistics are presented in table 5. Hyperuricemia was significantly associated with HTN (odds ratio 2.5; 95\% CI 1.8 to 23.4; $\mathrm{p}<0.0001)$. Similarly, hyperuricemia was significantly associated with the development of nephropathy and DKD/CKD; odds ratio 2.1 (95\% CI 1.46 to $2.8 ; \mathrm{p}<0.0001)$ and 27.3 (95\% CI 14 to 53; $\mathrm{p}<0.0001$ ), respectively.

ROC for DKD and serum uric acid demonstrated that with AUC of 0.98 (95\% CI 0.961 to 0.986 ), UA level of 6.8 was $91 \%$ sensitive and $79 \%$ specific for the development and significantly associated with $\mathrm{DKD} / \mathrm{CKD}(\mathrm{p}<0.0001)$. This is presented graphically in figure 2 .

\section{Discussion}

Our data has proved for the first time involvement and an association

Table 1: Demographic data of diabetic patients.

\begin{tabular}{|l|c|c|}
\hline \multirow{2}{*}{ Variables } & \multicolumn{2}{|c|}{ N (\%); Totals=10300 } \\
\hline \multirow{2}{*}{ Gender } & Male & Female \\
\cline { 2 - 3 } & $6077(59 \%)$ & $4223(41 \%)$ \\
\hline \multirow{2}{*}{ Hypertension } & Positive & Negative \\
\cline { 2 - 3 } & $4326(42 \%)$ & $5974(58 \%)$ \\
\hline \multirow{2}{*}{ Nephropahty } & Positive & Negative \\
\cline { 2 - 3 } & $3811(37 \%)$ & $6489(63 \%)$ \\
\hline \multirow{2}{*}{$\begin{array}{l}\text { Diabetic Kidney Disease } \\
\text { (DKD/CKD) status }\end{array}$} & Positive & Negative \\
\hline \multirow{2}{*}{ Hyperuricemia } & $1648(16 \%)$ & $8652(84 \%)$ \\
\cline { 2 - 3 } & Positive & Negative \\
\cline { 2 - 3 } & $1751(17 \%)$ & $8549(\%)$ \\
\hline
\end{tabular}

Table 2: Variables with Mean \pm SD.

\begin{tabular}{|l|c|}
\hline \multicolumn{1}{|c|}{ Variables } & Mean \pm SD \\
\hline Age (Years) & $53 \pm 12.5$ \\
\hline Diabetes duration (Years) & $16 \pm 8.5$ \\
\hline Serum creatinine $(\mathrm{mg} / \mathrm{dl})$ & $0.964 \pm 0.677$ \\
\hline Serum uric acid & $5.8 \pm 2.7$ \\
\hline Systolic BP $(\mathrm{mmHg})$ & $128 \pm 15.6$ \\
\hline Diastolic BP $(\mathrm{mmHg})$ & $80 \pm 9.2$ \\
\hline Microalbumin in urine $(\mathrm{mg} / \mathrm{L})$ & $73.4 \pm 105.5$ \\
\hline Spot Urine protein $(\mathrm{mg} / \mathrm{dl})$ & $52.7 \pm 28.8$ \\
\hline
\end{tabular}


Table 3: T-test between groups of variables (with and without foot ulcer) with Mean \pm SD and P-values.

\begin{tabular}{|c|c|c|c|c|c|}
\hline Variables and indicators & & Comparison o & les & & \\
\hline \multirow{10}{*}{ Serum Uric Acid concentration } & Mean $\pm 95 \% \mathrm{Cl}$ & & $\begin{array}{c}F \\
\text { value }\end{array}$ & $\begin{array}{c}T \\
\text { value }\end{array}$ & $\begin{array}{c}P \\
\text { value }\end{array}$ \\
\hline & With HTN & Without HTN & & & \\
\hline & $5.8 \pm 3.4$ & $4.8 \pm 1.4$ & 3.5 & 4.9 & $<0.0001$ \\
\hline & 5.3-5.95 & $4.7-4.9$ & & & \\
\hline & With Nephropathy & Without Nephropathy & & & \\
\hline & $5.6 \pm 3.5$ & $4.9 \pm 1.4$ & 4.6 & 3.7 & $<0.0001$ \\
\hline & $5.2-5.9$ & $4.8-5$ & & & \\
\hline & With DKD & Without DKD & & & \\
\hline & $7 \pm 1$ & $4.6 \pm 1$ & 2.4 & 32.5 & $<0.0001$ \\
\hline & $6.9-7.3$ & $4.4-4.6$ & & & \\
\hline \multirow{3}{*}{ Serum Creatinine (mg/dl) } & Hyperuricemia Yes & Hyperuricemia No & & & \\
\hline & $1.52 \pm 1.1$ & $0.81 \pm 0.42$ & 114.3 & 13.74 & $<0.0001$ \\
\hline & $1.38-1.67$ & $0.8-0.88$ & & & \\
\hline \multirow{3}{*}{ Systolic BP (mmHg) } & Hyperuricemia Yes & Hyperuricemia No & & & \\
\hline & $135 \pm 20$ & $126 \pm 15$ & 14.2 & 6.2 & $<0.0001$ \\
\hline & $132-138$ & $125-128$ & & & \\
\hline \multirow{3}{*}{$\begin{array}{l}\text { Diastolic BP } \\
(\mathrm{mmHg})\end{array}$} & Hyperuricemia Yes & Hyperuricemia No & & & \\
\hline & $82 \pm 10$ & $78 \pm 9$ & 3.9 & 4.9 & $<0.0001$ \\
\hline & $81-84$ & $77-79$ & & & \\
\hline \multirow{3}{*}{$\begin{array}{l}\text { Urine Microalbumin } \\
\text { (mg/L) }\end{array}$} & Hyperuricemia Yes & Hyperuricemia No & & & \\
\hline & $195 \pm 176$ & $62 \pm 48$ & 34.8 & 4.5 & $<0.0001$ \\
\hline & $131.2-297$ & $54-72$ & & & \\
\hline \multirow{3}{*}{ Spot Urine Protein (mg/dl) } & Hyperuricemia Yes & Hyperuricemia No & & & \\
\hline & $145 \pm 95$ & $26 \pm 17$ & 39.5 & 4.8 & $<0.0001$ \\
\hline & $76-245$ & $24-49$ & & & \\
\hline
\end{tabular}

Table 4: Pearson's correlations between variables with P-values.

\begin{tabular}{|l|c|c|}
\hline \multicolumn{1}{|c|}{ Variables } & $\begin{array}{c}\text { Pearson } \\
\text { Correlation (r) }\end{array}$ & P-value \\
\hline Serum creatinine and Uric Acid & 0.4 & $<0.0001$ \\
\hline Serum Uric Acid and Systolic BP & 0.26 & $<0.0001$ \\
\hline Serum Uric Acid and Diastolic BP & 0.21 & $<0.0001$ \\
\hline Serum Uric Acid and Urine Microalbumin & 0.22 & $<0.0001$ \\
\hline Serum Uric Acid and Spot Urine Protein & 0.24 & $<0.0001$ \\
\hline
\end{tabular}

of serum UA with HTN, elevated serum creatinine and development of $\mathrm{DKD} / \mathrm{CKD}$ among diabetics.

Furthermore our statistics for the first time has demonstrated that high levels of UA were also responsible for the proteinuria (microalbuminuria and spot urine proteins). Apart from microalbuminuria screening, spot urine protein excretion has been also demonstrated for the detection, diagnosing and monitoring DKD [16]. In our study, in addition to microalbumin, we used also spot urine protein excretion and its association with hyperuricemia. The data has demonstrated a very significant association between these two variables $(\mathrm{p}<0.0001)$.

Furthermore, recent research evidence suggests that high serum UA levels are associated with co-morbidities, microvascular and macrovascular complications including essential hypertension, progression of nephropathy, stroke and cardiovascular mortality
[17-21]. High serum UA causes increased excretion of UA from the kidney which results in supersaturated urine, crystallization of urate, and obstruction of renal tubules, granulomatous inflammation, ultimately damaging the kidney and causing a decline in impairment in renal function. These pathologies are also referred to as "acute urate nephropathy". If untreated, this condition may cause Acute Renal Failure (ARF) or Acute Kidney Injury (AKI) [22,23]. Moreover, it has been also proven that the treatment with Allopurinol normalizes endothelial dysfunction in type 2 diabetics with mild hypertension [24], which provides the evidence that hyperurecemia was responsible for endothelial dysfunction and HTN. Hence, management of high UA lowering agents have shown beneficial effects on renal and cardiovascular systems $[25,26]$, which should be considered in such patients.

Hyperuricemias and gout have been well discovered in other specific types of diabetes such as the mature onset of diabetes (HNF1BMODY), which often presents at youth. Such MODY subtype is also associated with nephropathy which warrants for genetic screening and testing in such patients (including family members) for confirmation of diagnosis [27-32].

It is now clear that UA is a definitive cardiovascular risk factor in hypertension [33]. However, previous studies have not demonstrated $\mathrm{UA}$ as a risk for essential hypertension, proteinuria, and renal dysfunction among type-2 diabetic patients, which was achieved in the current study. Our data clearly demonstrates that out of 10,300 patients, $17 \%$ had hyperuricemia. Significant correlations were found between UA and other variables (Serum creatinine, systolic and 
diastolic BP, microalbumin and spot urine protein). Subjects labelled as HTN, nephropathy and DKD/CKD have demonstrated higher UA levels. Higher serum UA concentrations were significantly associated with proteinuria in our data. Table 3 and figure 1 emphasizing the significance of renal involvement in the diabetic state. Binary logistic regression and odds ratio have also proven the significant associations between hyperuricemia and HTN, nephropathy and DKD/CKD (Table 5). Additionally, regression model between serum UA and serum creatinine was also significantly associated with each other and proves our hypothesis that UA linearly causes an increase in the blood creatinine with the following relationship : Serum creatinine $=0.221$ $+[0.154 \times$ serum UA $]$. These associations were first demonstrated in our study. Moreover, in the past no study has found cut off points for serum UAs for the development of DKD/CKD among diabetics with sensitivity and specificity. We constructed ROC for 10,300 patients to find UA cut off points. Our data demonstrated that with AUC 0.98 (95\% CI 0.961 to 0.986 ), UA cut off level of $6.8 \mathrm{mg} / \mathrm{dl}$ was $91 \%$ sensitivity and $80 \%$ specificity for the development of renal impairment (DKD/ $\mathrm{CKD}$ ) among type- 2 diabetics ( $\mathrm{p}<0.0001$; table 5 and figure 2 ). Hence, according to our data, UA levels of $6.8 \mathrm{mg} / \mathrm{dl}$ should be alarming to the diabetologist, endocrinologist, internal medicine, and primary care physicians to initiate dietary interventions or pharmacological management to prevent further diabetes related complications. Further, multicenter studies are required internationally to confirm the findings of our study.

\section{Conclusion and Recommendations}

Our study has given a message to physicians that diabetic patients should be screened for hyperuricemia. Our data has demonstrated

Table 5: Pearson's $\left(\chi^{2}\right)$, logistic regression/odd ratio, regression model and ROC.

\begin{tabular}{|c|c|c|c|c|c|}
\hline Variables & $\begin{array}{l}\text { Pearson's }\left(x^{2}\right) \\
\text { p-value }\end{array}$ & $\begin{array}{c}\text { Fisher's exact test } \\
\text { p-value }\end{array}$ & $\begin{array}{l}\text { Linear-by-linear } \\
\text { Association } \\
\text { p-value }\end{array}$ & \multicolumn{2}{|c|}{$\begin{array}{c}\text { Logistic } \\
\text { Regression and } \\
\text { Odds Ratio }(95 \% \mathrm{Cl}) \\
\end{array}$} \\
\hline Hyperuricemia and HTN & $<0.0001$ & $<0.0001$ & $<0.0001$ & \multicolumn{2}{|c|}{2.5 (1.8 to 3.4$)$} \\
\hline $\begin{array}{l}\text { Hyperuricemia and } \\
\text { Nephropathy }\end{array}$ & $<0.0001$ & $<0.0001$ & $<0.0001$ & \multicolumn{2}{|c|}{2.1 (1.46 to 2.8$)$} \\
\hline Hyperuricemia and DKD & $<0.0001$ & $<0.0001$ & $<0.0001$ & \multicolumn{2}{|c|}{27.3 (14 to 53$)$} \\
\hline \multicolumn{6}{|c|}{ Regression Analysis and Model for Serum Uric Acid and Creatinine } \\
\hline $\mathbf{R}^{2}$ & F Statistic & $\begin{array}{l}\text { ANOVA Model } \\
\text { P-Value }\end{array}$ & T Statistic & P-Value & Regression Equation \\
\hline 0.16 & 117 & $<0.0001$ & 2.9 & $<0.0001$ & $\begin{array}{c}\text { Serum creatinine }= \\
0.221+[0.154 \times \text { serum uric } \\
\text { acid }]\end{array}$ \\
\hline \multicolumn{6}{|c|}{ ROC Statistics } \\
\hline Test variables & $(A \cup C)$ & $\begin{array}{l}\text { Standard } \\
\text { error }\end{array}$ & $95 \% \mathrm{Cl}$ & P-Value & $\begin{array}{l}\text { Uric acid coordinates } \\
\text { and cutoff points for the } \\
\text { development of DKD }\end{array}$ \\
\hline $\begin{array}{l}\text { DKD and serum uric } \\
\text { acid }\end{array}$ & 0.98 & 0.006 & $0.961-0.986$ & $<0.0001$ & $\begin{array}{c}6.8 \mathrm{mg} / \mathrm{dl} \\
\text { (91\% sensitivity and } 80 \% \\
\text { specificity) }\end{array}$ \\
\hline
\end{tabular}

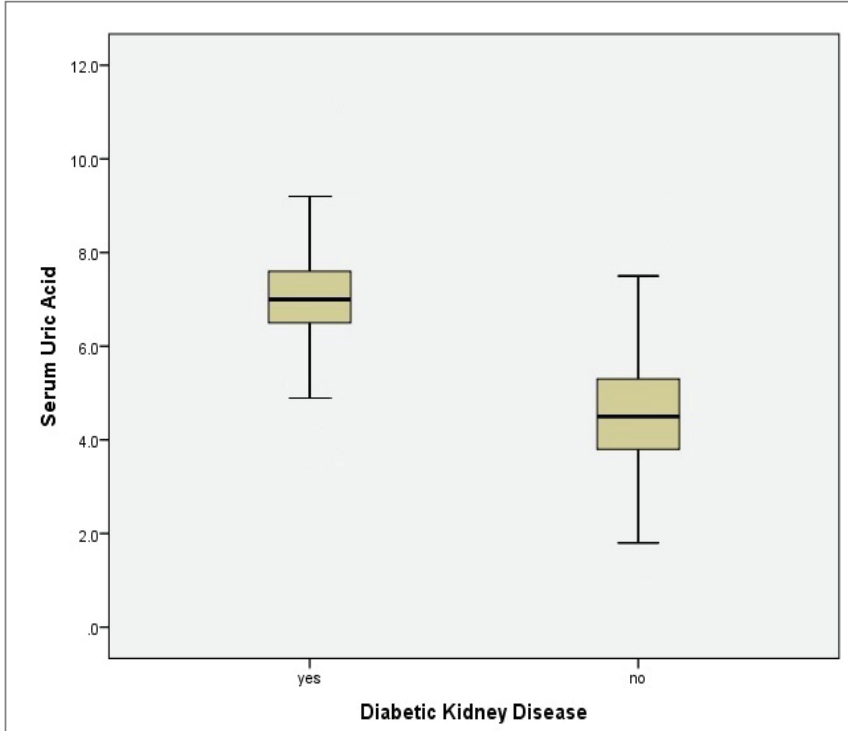

Figure 1: Box plot of serum uric acid levels with or without DKD.

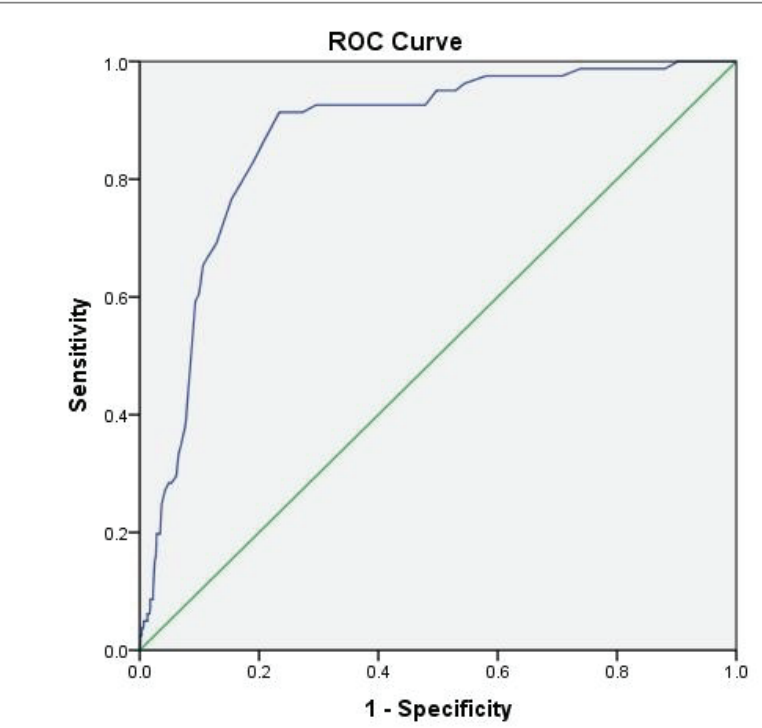

Figure 2: ROC of serum uric acid and Diabetic Kidney Disease (DKD). 
significant associations of UA with HTN, nephropathy and diabetic kidney disease. It is the time to revise the normal levels of UA among type-2 diabetics. If UA levels reach up $6.8 \mathrm{mg} / \mathrm{dl}$, then the healthcare provider must educate and counsel the patients with lifestyle and dietary advises (dietitian nutritional counselling). If the goals are not achieved then pharmacotherapy should be considered to prevent UA diabetes related complications.

\section{Conflict of Interest}

Author declares no conflict of interest. This study was not funded by any organization and author himself collected the data with literature search, statistical analysis and paper writing.

\section{References}

1. Aziz KMA (2017) Association of Serum Lipids with High Blood Pressure and Hypertension among Diabetic Patients. Mathematical Regression Models to Predict Blood Pressure from Lipids. An Experience from 12-year Follow Up of more than 9000 Patients' Cohort. Gen Med (Los Angeles) 5.

2. Aziz KMA (2019) Association of High Levels of Spot Urine Protein with High Blood Pressure, Mean Arterial Pressure and Pulse Pressure with the Development of Diabetic Chronic Kidney Dysfunction or Failure among Diabetic Patients. Statistical Regression Modeling to Predict Diabetic Proteinuria. Curr Diabetes Rev 15: 486-496.

3. Gois PH, de Moraes Souza ER (2013) Pharmacotherapy for hyperuricemia in hypertensive patients. Cochrane Database Syst Rev CD008652.

4. Galvan AQ, Natali A, Baldi S, Frascerra S, Sanna G, et al. (1995) Effect of insulin on uric acid excretion in humans. Am J Physiol 268: E1-E5.

5. Dehghan A, van Hoek M, Sijbrands EJ, Hofman A, Witteman JC (2008) High serum uric acid as a novel risk factor for type 2 diabetes. Diabetes care 31: 361-362.

6. Johnson RJ, Nakagawa T, Sanchez-Lozada LG, Shafiu M, Sundaram $S$, et al. (2013) Sugar, uric acid, and the etiology of diabetes and obesity. Diabetes 62: 3307-3315.

7. Kodama S, Saito K, Yachi Y, Asumi M, Sugawara A, et al. (2009) Association between serum uric acid and development of type 2 diabetes. Diabetes care 32: 1737-1742.

8. Bhole V, Choi JW, Kim SW, de Vera M, Choi H (2010) Serum uric acid levels and the risk of type 2 diabetes: a prospective study. Am J Med 123: 957-961.

9. Brand FN, McGee DL, Kannel WB, Stokes J $3^{\text {rd }}$, Castelli W (1985) Hyperuricemia as a risk factor of coronary heart disease: The Framingham Study. Am J Epidemiol 121: 11-18.

10. Abbott RD, Brand FN, Kannel WB, Castelli WP (1988) Gout and coronary heart disease: the Framingham Study. J Clin Epidemiol 41: 237-242.

11. Culleton BF, Larson MG, Kannel WB, Levy D (1999) Serum uric acid and risk of cardiovascular disease and death: the Framingham Heart Study. Ann Intern Med 31: 7-13.

12. Persky VW, Dyer AR, Idris-Soven E, Stamler J, Shekelle RB, et al. (1979) Uric acid: a risk factor for coronary heart disease? Circulation 59: 969-977.

13. Lai LH, Chou SY, Wu FY, Chen JJ, Kuo HW (2008) Renal dysfunction and hyperuricemia with low blood lead levels and ethnicity in community-based study. Sci Total Environ 401: 39-43.
14. Aziz KMA (2014) Association of Microalbuminuria with Ischemic Heart Disease, Dyslipidemia and Obesity among Diabetic Patients: Experience from 5 Year Follow up Study of 1415 Patients. Bioenergetics 3.

15. Aziz KMA (2016) Association of Hypothyroidism with Body Mass Index, Systolic Blood Pressure and Proteinuria in Diabetic Patients: Does treated Hypothyroidism with Thyroxine Replacement Therapy Prevent Nephropathy/Chronic Renal Disease? Curr Diabetes Rev 12: 297-306.

16. Aziz KMA (2015) Correlation of Urine Biomarkers: Microalbuminuria and Spot Urine Protein among Diabetic Patients. Application of Spot Urine Protein in Diabetic Kidney Disease, Nephropathy, Proteinuria Estimation, Diagnosing and Monitoring. Recent Pat Endocr Metab Immune Drug Discov 9: 121-133.

17. Kang DH, Nakagawa T, Feng L, Watanabe S, Han L, et al. (2002) A role for uric acid in the progression of renal disease. J Am Soc Nephrol 13: 2888-2897.

18. Messerli FH, Frohlich ED, Dreslinski GR, Suarez DH, Aristimuno GG (1980) Serum uric acid in essential hypertension: an indicator of renal vascular involvement. Arch Intern Med 93: 817-821.

19. Verdecchia P, Schilllaci G, Reboldi GP, Santeusanio F, Porcellati C, et al. (2000) Relation between serum uric acid and risk of cardiovascular disease in essential hypertension. The PIUMA Study. Hypertension 36: 1072-1078.

20. Fang J, Alderman MH (2000) Serum uric acid and cardiovascular mortality the NHANES I epidemiologic follow-up study, 1971-1992. National Health and Nutrition Examination Survey. JAMA 283: 24042410.

21. Lehto S, Niskanen L, Rönnemaa T, Laakso M (1998) Serum uric acid is a strong predictor of stroke in patients with non-insulin-dependent diabetes mellitus. Stroke 29: 635-639.

22. Ryu ES, Kim MJ, Shin HS, Jang YH, Choi HS, et al. (2013) Uric acidinduced phenotypic transition of renal tubular cells as a novel mechanism of chronic kidney disease. Am J Physiol Renal Physiol 304: F471-F480.

23. Basile DP (2004) Rarefaction of peritubular capillaries following ischemic acute renal failure: a potential factor predisposing to progressive nephropathy. Curr Opin Nephrol Hypertens 13: 1-7.

24. Butler R, Morris AD, Belch JJ, Hill A, Struthers AD (2000) Allopurinol normalizes endothelial dysfunction in type 2 diabetics with mild hypertension. Hypertension 35: 746-751.

25. Ronco C, Inguaggiato P, Bordoni V, De Cal M, Bonello M, et al. (2005) Rasburicase therapy in acute hyperuricemia and renal dysfunction. Contrib Nephrol 147: 115-123.

26. Moreau D (2005) Pharmacological treatment of acute renal failure in intensive care unit patients. Contrib Nephrol 147: 161-173.

27. American Diabetes Association (2020) 4. Comprehensive medical evaluation and assessment of comorbidities: Standards of Medical Care in Diabetes-2020. Diabetes Care 43: S37-S47.

28. Omura Y, Yagi K, Honoki H, Iwata M, Enkaku A, et al. (2019) Clinical manifestations of a sporadic maturity-onset diabetes of the young (MODY) 5 with a whole deletion of HNF1B based on $17 q 12$ microdeletion. Endocr J 66: 1113-1116.

29. Nagano C, Morisada N, Nozu K, Kamei K, Tanaka R, et al. (2019) Clinical characteristics of HNF1B-related disorders in a Japanese population. Clin Exp Nephrol 23: 1119-1129. 
30. Okorn C, Goertz A, Vester U, Beck BB, Bergmann C, et al. (2019) HNF1B nephropathy has a slow-progressive phenotype in childhoodwith the exception of very early onset cases: results of the German Multicenter HNF1B Childhood Registry. Pediatr Nephrol 34: 10651075.

31. Shields BM, Hicks S, Shepherd MH, Colclough K, Hattersley AT, et al. (2010) Maturity-onset diabetes of the young (MODY): how many cases are we missing? Diabetologia 53: 2504-2508.

32. Naylor RN, John PM, Winn AN, Carmody D, Greeley SA, et al. (2014) Cost-effectiveness of MODY genetic testing: translating genomic advances into practical health applications. Diabetes care 37: 202209.

33. Puig JG, Ruilope LM (1999) Uric acid as a cardiovascular risk factor in arterial hypertension. J Hypertens 17: 869-872. 